\title{
Biochar from Oil Cakes: An Efficient Adsorbent for the Removal of Acid Dyes From Wool Dye House Effluent
}

seiko jose ( $\sim$ seiko_jose2005@yahoo.co.in )

Central Sheep and Wool Research Institute

Reena Roy

Assam Agricultural University Faculty of Home Science

Ava Phukan

Assam Agricultural University Faculty of Home Science

Dinesh Shakyawar

Central Sheep and Wool Research Institute

Anuradha Sankaran

PSNA College of Engineering and Technology

\section{Research Article}

Keywords: Acid dyes, Biochar, Dye removal, Effluent treatment, Oil cakes

Posted Date: August 17th, 2021

DOl: https://doi.org/10.21203/rs.3.rs-795342/v1

License: (c) (i) This work is licensed under a Creative Commons Attribution 4.0 International License. Read Full License

Version of Record: A version of this preprint was published at Clean Technologies and Environmental Policy on January 17th, 2022. See the published version at https://doi.org/10.1007/s10098-021-02253-2. 
3 Seiko Jose $^{1 *}$, Reena Roy ${ }^{2}$, Ava Rani Phukan ${ }^{2}$, Dinesh Babu Shakyawar ${ }^{1}$, AnuradhaSankaran ${ }^{3}$

$4{ }^{1}$ Textile Manufacturing and Textile Chemistry Division, ICAR - Central Sheep and Wool Research Institute, 5 Avikanagar, India, 304501

$6 \quad{ }^{2}$ Department of Textiles and Apparel Design, Assam Agricultural University, Jorhat, Assam, India, 785013

$7 \quad{ }^{3}$ Department of Chemistry, PSNA College of Engineering and Technology, Dindigul, Tamil Nadu, India, 624622

8

$9 \quad *$ Corresponding author

10 Email :seiko_jose2005@yahoo.co.in

11

12

\section{Abstract}

\section{Introduction}

Textile dyeing industries are one of the major culprits for environmental pollution. The industries are adopting various processes for the removal of dyes and chemicals from the effluent before disposing to the land or water bodies. In the reported study, biochars were prepared from almond, coconut, and mustard oil cakes by chemical activation with phosphoric acid followed by low temperature pyrolysis. The ball milling technique was employed to reduce the particle size of the biochars below $300 \mathrm{~nm}$. The synthesized biochars were used for the removal of color from the acid dye effluent from the wool dyeing unit. The results showed that very small quantities $(2.0 \%)$ of biochars are sufficient to remove around $92 \%$ color from the dye effluent. The batch adsorption and kinetic studies indicate the highest efficiency of color removal for the biochar derived from almond oil cake, followed by mustard and coconut. The adsorption properties of the synthesized biochars were found to be greatly depending on the type of oil cake used. It is concluded that the biochars produced from the oil cakes may be a partial replacement of petroleum based activated carbon for the color removal from wool textile dye effluent.

Key words : Acid dyes, Biochar, Dye removal, Effluent treatment, Oil cakes

Textile industries opened up large employment opportunities in many countries. On another hand, they are causing environmental pollution also. Many countries imposed stringent regulations for the disposal of dye effluents to the land or nearby water bodies. The buyers are also conducting strict auditing in their production units to ensure that the supplier is maintaining all ecological regulations from the raw material to the end product. Thus, to fulfill the government regulations and customer demands, the textile industry need to stick on eco-friendly processing 
31 techniques to the maximum possible extent. The use of enzymes for pretreatment, high exhaustive dyes, and herbal colors are some of the good initiative steps taken in this regard.

During the dyeing process, depending upon the class of dye and the nature of the textile fiber, it is estimated that $15-20 \%$ of the dyes remained in the dye bath and discharged as effluent. The dye house effluents may contain heavy metals, ammonia, acids, alkalies, salts, and large amounts of pigments, many of which are toxic and low bio-degradable materials (Crini, 2006; Mohan and Karthikeyan., 2004). The textile industrial effluents are subjected to various treatments before discharging into the water bodies or land. The main methods used to treat colored effluents are oxidation, coagulation, flocculation, biological treatment, and membrane filtration. The disposal of improperly treated dye house effluent may cause a menace to the quality of the receiving water bodies, the aquatic eco-system, and humans due to objectionable color, odor, high BOD and COD, TDS, and other toxic compounds (Jose et al., 2020 a). In particular, acid dyes are widely employed in wool and silk dying industries. Such textile dyes are typically very stable with half-lives of $2-13$ years in the environment, and they have been detected in several rivers, lakes, and terrestrial soils, causing toxicological problems to the aquatic environment (Copaciu et al., 2016).

Land disposal or burning is the most common disposal method adopted by farmers and industries, which causes land, aquatic, and air pollution. There is an increase in research interest is observed in the scientific community to covert the agro residues generated during cultivation, harvesting, and processing of crops into useful outcomes. Many of the agro-residues have been used for the preparation of textiles, dyes, enzymes, activated carbon, etc (Jose et al., 2020). Oil cakes as an agro-residue are obtained after the extraction of oil from dried kernels. Early days, oil cakes had not acquired much commercial value except as feed for cattle and poultry. However, new technologies open up enormous potential for oil cakes and it is reported to have the potentiality in the production of enzymes, antioxidants, antibiotics, vitamins, biopesticides, etc (Ramachandran et al., 2007).

Pyrolysis is the conventional method of preparation of activated carbon and biochar. During this process, the biomass is converted into carbon by the release of volatile matter. The yield and properties of the activated carbon and biochar greatly depend on the raw materials, activating chemicals, and pyrolysis conditions (Yuan et al., 2020). The high cost effect of activated carbon restricts its use as a commercial adsorbent. Biochars prepared from agro-residues such as rice husk, rice straw, hazelnut shell, pine needles, wheat straw, sunflower straw, etc, could find potential applications in pesticide and heavy metal removal (Dawood et al., 2017), fertilizer, porous carbon 
catalysts (Wang et al.,2019 ; Panahi, et al., 2020; Vaughn et al., 2018), etc. A dearth of literature is available on the preparation of biochar from oil cakes.

In the present attempt, biochars were prepared from almond, coconut, and mustard oil cakes through chemical activation followed by pyrolysis. The physical and adsorption characteristics of the biochars were investigated. The synthesized biochars were employed for the removal of color from acid dyes of real textile dye effluent from the wool processing pilot plant using batch adsorption experimental studies.

\section{Material and Methods}

Oil cakes used for the study were collected directly from oil mills from various locations of India and used without further purification. Optilan Turquiose (acid dye) was purchased from local dye suppliers, Jaipur, India. Chemicals viz, orthophosphoric acid (assay - $98 \%$ ), and acetic acid (assay - 99.5\%), were purchased from Merck, India.

\subsection{Collection of dye effluent}

The effluent used for the study was taken from the wool dyeing pilot plant at M/S Central Sheep and Wool Research Institute, Avikanagar, Rajasthan, India. The dyeing of wool fabric with acid dye (10 g/l Optilan Turquiose) was performed by maintaining 1:20 material to liquid ratio (MLR) keeping the $\mathrm{pH} 5.0$ using acetic acid. The dyeing was carried out at $90{ }^{\circ} \mathrm{C}$ for 30 min without using any auxiliaries, except $0.5 \mathrm{~g} / \mathrm{L}$ nonionic wetting agent (Ultravon, JU). After dyeing, the effluent was collected, filtered, and used for the characterization and batch experimental studies.

\subsection{Preparation of biochars}

The oil cakes of almond, coconut, and mustard were pulverized in a grinder. The finely powdered oil cakes were filtered through 200 mesh size nylon filter to get particles of almost the same size. Three hundred grams of each powder were individually triggered to acid activation separately using $1.0 \mathrm{~N}$ and $2.5 \mathrm{~N}$ orthophosphoric acid for $24 \mathrm{~h}$, with continuous stirring in a mechanical shaker. The impregnation ratio of acid to oil cakes was kept at 4:1. After acidification, the oil cakes were squeezed to remove the acid and dried at $105{ }^{\circ} \mathrm{C}$ for $60 \mathrm{~min}$. The dried oil cakes were then charred and further pyrolysed in a muffle furnace at $350^{\circ} \mathrm{C}$ for $2 \mathrm{~h}$ with a heating rate of $20^{\circ} \mathrm{C} / \mathrm{min}$ in air atmosphere. The biochar thus obtained was washed with hot and then cold water to attain neutral $\mathrm{pH}$ and dried.

The yield of biochar was calculated using the equation (1), 
The particle size of the biochars was further reduced by $2 \mathrm{~h}$ of ball milling in Pulverisette (model- 6 ClassicLine, Fritsch, Russia).To narrow down the experiment, a preliminary exercise was conducted. The dye effluent was treated with $0.5 \%$ weight percentage of each adsorbent for $30 \mathrm{~min}$ and the absorbency values were noted (Table 1). Based on the absorbency value, the best one from each oil cake was selected for further characterization and batch adsorption studies, namely $2.5 \mathrm{~N} \mathrm{PAB}, 1.0 \mathrm{~N} \mathrm{PCB}$, and 2.5 N PMB.

Table 1. Absorbency values of biochar prepared from oil cakes

\begin{tabular}{|c|c|c|c|}
\hline S. No & Biochars & Abbreviation & Absorbency \\
\hline 1 & $1.0 \mathrm{~N} \mathrm{H}_{3} \mathrm{PO}_{4}$ treated almond oil cake biochar & $1.0 \mathrm{~N} \mathrm{PAB}$ & 1.20 \\
\hline 2 & $2.5 \mathrm{~N} \mathrm{H}_{3} \mathrm{PO}_{4}$ treated almond oil cake biochar & $2.5 \mathrm{~N} \mathrm{PAB}$ & 1.15 \\
\hline 3 & $1.0 \mathrm{~N} \mathrm{H}_{3} \mathrm{PO}_{4}$ treated coconut oil cake biochar & $1.0 \mathrm{~N} \mathrm{PCB}$ & 1.27 \\
\hline 4 & $2.5 \mathrm{~N} \mathrm{H}_{3} \mathrm{PO}_{4}$ treated coconut oil cake biochar & $2.5 \mathrm{~N} \mathrm{PCB}$ & 1.22 \\
\hline 5 & $1.0 \mathrm{~N} \mathrm{H}_{3} \mathrm{PO}_{4}$ treated mustard oil cake biochar & $1.0 \mathrm{~N} \mathrm{PMB}$ & 1.10 \\
\hline 6 & $2.5 \mathrm{~N} \mathrm{H}_{3} \mathrm{PO}_{4}$ treated mustard oil cake biochar & $2.5 \mathrm{~N} \mathrm{PMB}$ & \\
\hline
\end{tabular}

\subsection{Characterization of biochars}

The particle size of biochar was analyzed using the Malvern Mastersizer (model - 3000) particle size analyzer. FTIR analysis was performed for the identification of functional groups present in the bare oil cakes and the synthesized biochar using the Brucker double beam spectrophotometer (model - Alpha). The spectra were measured from $4000-500 \mathrm{~cm}^{-1}$. Dispersion $(0.1 \%)$ of biochar in water was sonicated before feeding to the particle size analyzer to deter agglomeration. The morphology of the biochar was analyzed by SEM analysis using Nova Nano FESEM-450 (Netherland) with suitable magnification. X-ray diffraction analysis was conducted using a Panalytical X'pert powder diffractometer. The surface area analysis of the biochars was performed using Nova Touc LX2 b Quantachromme instrument to obtain the adsorption isotherm and the surface area was calculated by Brunauer-Emmett Teller (BET) method.

\subsection{Analysis of physical and adsorption properties of biochars}

About $0.1 \mathrm{~g}$ of the biochars was added to $30 \mathrm{ml}$ distilled water and boiled for 10 minutes. The solution was brought to room temperature and filtered. The $\mathrm{pH}$ of the solution was measured with a pH meter (Hanna- HI98130). 
For the analysis of bulk density, $3.0 \mathrm{~g}$ of adsorbent was taken in a $10 \mathrm{ml}$ measuring cylinder and tightly packed without voids. The density was determined from the ratio of mass to volume. Adsorbent $(0.5 \mathrm{~g})$ was kept at $105{ }^{\circ} \mathrm{C}$ for $6 \mathrm{~h}$. The moisture content of the adsorbent was analyzed from the difference in the weights before and after drying. For porosity measurement, $2.5 \mathrm{ml}$ distilled water was added to $1.5 \mathrm{~g}$ adsorbent in a $10 \mathrm{ml}$ measuring cylinder. The volume of the cylinder was recorded $\left(\mathrm{V}_{1}\right)$ initially and after one hour $\left(\mathrm{V}_{2}\right)($ Pongener et. al., 2015).The methylene blue value was determined by dissolving $1.2 \mathrm{~g}$ methylene dye in a1000 $\mathrm{ml}$ standard measuring flask with the aid of $0.25 \%(\mathrm{v} / \mathrm{v})$ acetic acid. The absorbance of the solution was then adjusted to 0.84 at $620 \mathrm{~nm}$ by dilution. Added $0.1 \mathrm{~g}$ of the biochar sample with $25 \mathrm{ml}$ of the methylene blue test solution in a volumetric flask and shaken until decolorization has occurred. The addition of methylene blue in the step of $5 \mathrm{ml}$ was continued till the saturation point, i.e., the color persists. The amount of methylene blue added was noted (Nunes and Guerreiro, 2011).

\subsection{Batch adsorption experiments}

The Optilan Turquiose acid dye effluent was treated with the selected biochars in a mechanical shaker with $200 \mathrm{rpm}$. The color removal efficiencies were recorded in terms of absorbance value. The experiments were conducted at $27{ }^{\circ} \mathrm{C}$ keeping the actual $\mathrm{pH}$ (6.9) of the acid dye effluent. The weight percentage of the adsorbents $(0.5,1.0,1.5$, and $2.0 \%)$ and the duration of treatment $(30,60$, and $90 \mathrm{~min})$ were kept as variables. After each experiment, the solution was centrifuged, filtered and the absorbency was measured using UV-Visible spectrophotometer (make- Systronics).

\subsection{Kinetic studies}

Upon performing the batch adsorption studies, it was observed that $2.5 \mathrm{~N}$ PAB is giving the maximum color removal. Thus, the kinetic study of 2.5 N PAB was carried out at different adsorbent dosages. The pseudo-first order rate equation (2) was used to calculate the adsorption capacity of the synthesized biochar given by the equation,

$$
\ln \left(q_{e}-q_{t}\right)=\ln q_{e}-k_{1} t
$$

where $q_{e}$ is the amount of dye adsorbed on adsorbent at equilibrium $(\mathrm{mg} / \mathrm{g}), q_{t}$ is the amount of dye adsorbed at any time $(\mathrm{mg} / \mathrm{g})$, and $k_{l}\left(\mathrm{~min}^{-1}\right)$ is the rate constant of the pseudo-first order adsorption which can be calculated from the slope of the linear plot of $\ln \left(q_{e}-q_{t}\right)$ against time. The pseudo-second order expression used to describe the rate of adsorption is presented by the equation (3), 
136 Where $k_{2}(\mathrm{~g} / \mathrm{mg} / \mathrm{min})$ is the rate constant of the pseudo-second order adsorption. $k_{2}$ and $q_{e}$ can be calculated from the

137 slope and intercept of the plot of $t / q_{\mathrm{t}} \mathrm{vs}$ time

\section{Results and Discussion}

\subsection{Properties of biochars}

The physical properties of the selected biochars are shown in Table 2. The yield of the biochar was found to be a maximum for $2.5 \mathrm{~N} \mathrm{PMB} \mathrm{(9.6 \% ),} \mathrm{followed} \mathrm{by} 1.0 \mathrm{~N} \mathrm{PCB}(9.4 \%)$, and $2.5 \mathrm{~N} \mathrm{PAB}(8.1 \%)$. During the charring process, the oil cakes undergo shrinkage and the weight loss may due to the loss of moisture content followed by decomposition of cellulosic material and removal of inorganic impurities as ash (Ding et al., 2014).The bulk density of the prepared $2.5 \mathrm{~N} \mathrm{PAB}(0.652 \mathrm{~g} / \mathrm{cc})$ was found to be slightly higher than the others. The value of the bulk density of the prepared bio chars is in between $0.50 \mathrm{~g} / \mathrm{cm}^{3}$ and $0.75 \mathrm{~g} / \mathrm{cm}^{3}$, which indicate that the prepared biochars are suitable for decolorization applications (Downie et al., 2009). The $\mathrm{pH}$ values of all synthesized biochars were found to be near neutral because of thorough washing with distilled water.

Table 2. Physical and adsorption properties of biochars

\begin{tabular}{|c|c|c|c|c|c|c|c|}
\hline & Yield & $\begin{array}{c}\text { Bulk } \\
\text { density } \\
(\%)\end{array}$ & $\begin{array}{c}\text { Moisture } \\
\text { content } \%)\end{array}$ & $\mathrm{pH}$ & $\begin{array}{c}\text { Methylene } \\
\text { blue value } \\
(\mathrm{mg} / \mathrm{g})\end{array}$ & $\begin{array}{c}\text { Porosity } \\
(\%)\end{array}$ & $\begin{array}{c}\text { Particle } \\
\text { size }(\mathrm{nm})\end{array}$ \\
\hline $2.5 \mathrm{~N} \mathrm{PAB}$ & 8.1 & 0.652 & 21.34 & 6.6 & 130 & 0.346 & $310(100)^{*}$ \\
\hline $1.0 \mathrm{~N}$ PCB & 9.4 & 0.625 & 12.13 & 6.7 & 105 & 0.323 & $113(100)^{*}$ \\
\hline $2.5 \mathrm{~N}$ PMB & 9.6 & 0.625 & 14.21 & 6.5 & 120 & 0.369 & $140(92)^{*}$ \\
\hline
\end{tabular}


the governing factors that determine the adsorption capacity of biochar is its porosity. The pores are formed in the biochar is due to the release of volatile organic matters. The highest porosity $(0.369 \%)$ was observed with $2.5 \mathrm{~N}$ PMB followed by $2.5 \mathrm{~N}$ PAB $(0.349 \%)$. The least porosity $(0.323 \%)$ was observed with biochar prepared from 1.0 N PCB. Ball milling is the common method adopting for the reduction of size of particles through grinding. Even after the same chemical treatment followed by the same period of ball milling, it is observed that the size of the biochar varies significantly depending on the source. The lowest particle size $(113 \mathrm{~nm})$ was observed in the case of 1.0 N PCB and the maximum was observed in the case of $2.5 \mathrm{~N} \mathrm{PAB}(310 \mathrm{~nm})$. From the particle size analysis of various biochars, it is observed that, among the three biochars, $2.5 \mathrm{~N} \mathrm{PAB}$ and $1.0 \mathrm{~N}$ PCB showed $100 \%$ distribution intensity and the $2.5 \mathrm{~N}$ PMB showed more than $90 \%$.This indicates that the ball milling process was done perfectly and as a result, all the particles in a single biochars showed almost the same particle size (Partlan et al., 2016). Thus, the physical and adsorption studies reveal that the properties of biochar greatly depend on the type of oil cake and concentration of activating acid.

\subsection{FTIR analysis}

Since in the batch adsorption studies of acid dyes, the biochar prepared from $2.5 \mathrm{~N}$ PAB gave the best performance, the FTIR study is being reported for the same in comparison with its source oil cake (Figure 1). The chemical activation of biochar might promote the surface functional groups and hence influence the adsorption property. In the case of pristine almond oil cake, the sharp peak at $3742 \mathrm{~cm}^{-1}$ corresponds to the $-\mathrm{OH}$ hydroxyl stretching, probably due to the presence of moisture in the oil cake. The band near $1743 \mathrm{~cm}^{-1}$ is assigned to stretching vibrations of the $\mathrm{C}=\mathrm{O}$ of the ester and aldehydic groups present in hemicelluloses and lignin (Basu et al., 2015). The bands around $2916 \mathrm{~cm}^{-1}$ are attributed to aliphatic C-H asymmetric stretching present mainly in cellulose, which is the major component of the lignocellulosic biomass (Adel et al., 2011). The broad peak at 1024 $\mathrm{cm}^{-1}$ region ascribed to $\mathrm{C}=\mathrm{O}, \mathrm{C}-\mathrm{H}, \mathrm{C}-\mathrm{O}-\mathrm{C}$, and $\mathrm{C}-\mathrm{O}$ deformation or stretching vibrations of different groups in cellulose, hemicellulose, and lignin (Pandey et al., 2019). The sharp, but slightly broad peak at $1515 \mathrm{~cm}^{-1}$ indicates the $\mathrm{C}=\mathrm{C}$ vibrations of the aromatic rings of lignin (Jose et al., 2017). The $\mathrm{C}=\mathrm{O}$ stretching vibration in conjugated carbonyl of lignin is shown at $1639 \mathrm{~cm}^{-1}$ and the aliphatic part of lignin at $1446 \mathrm{~cm}^{-1}$ (Shi and li, 2012). In the case of biochar, after chemical treatment followed by pyrolysis, most of the peaks were disappeared in comparison with pristine oil cake. The peak at $1639 \mathrm{~cm}^{-1}$ attribute to the removal of oxygen functional groups and the peak at 2916 $\mathrm{cm}^{-1}$ shows the decomposition of cellulosic structure and the appearance of a new peak at $1268 \mathrm{~cm}^{-1}$ may be due to 

biochar, the peak corresponding to hydroxyl group at $3734 \mathrm{~cm}^{-1}$ is slightly visible.

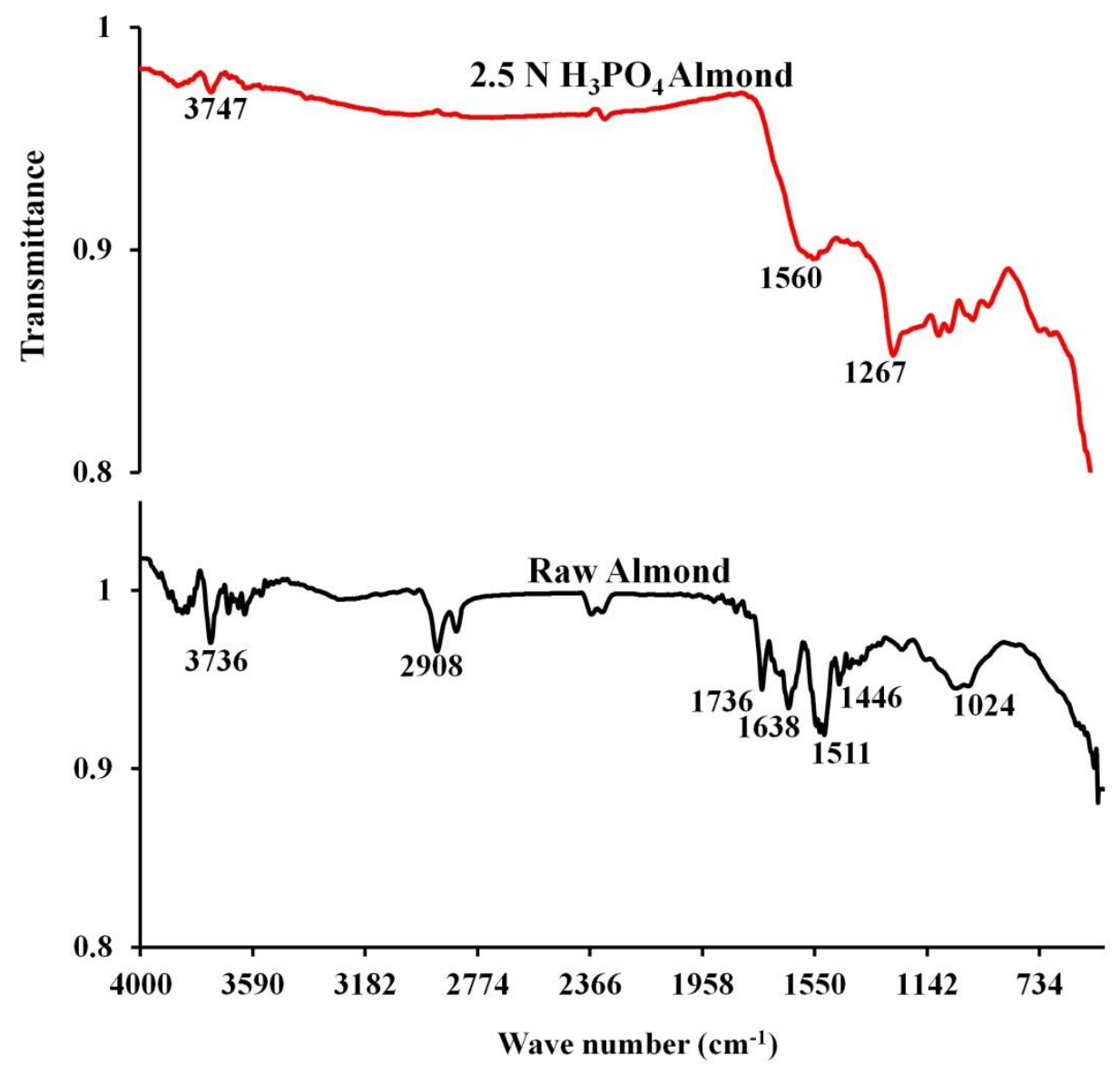

Fig. 1. FTIR spectra of raw almond oil cake and 2.5 NPAB with the diffraction of $\left(\begin{array}{lll}1 & 0 & 0\end{array}\right)$ respectively (Girgis, B.S., 2007). 


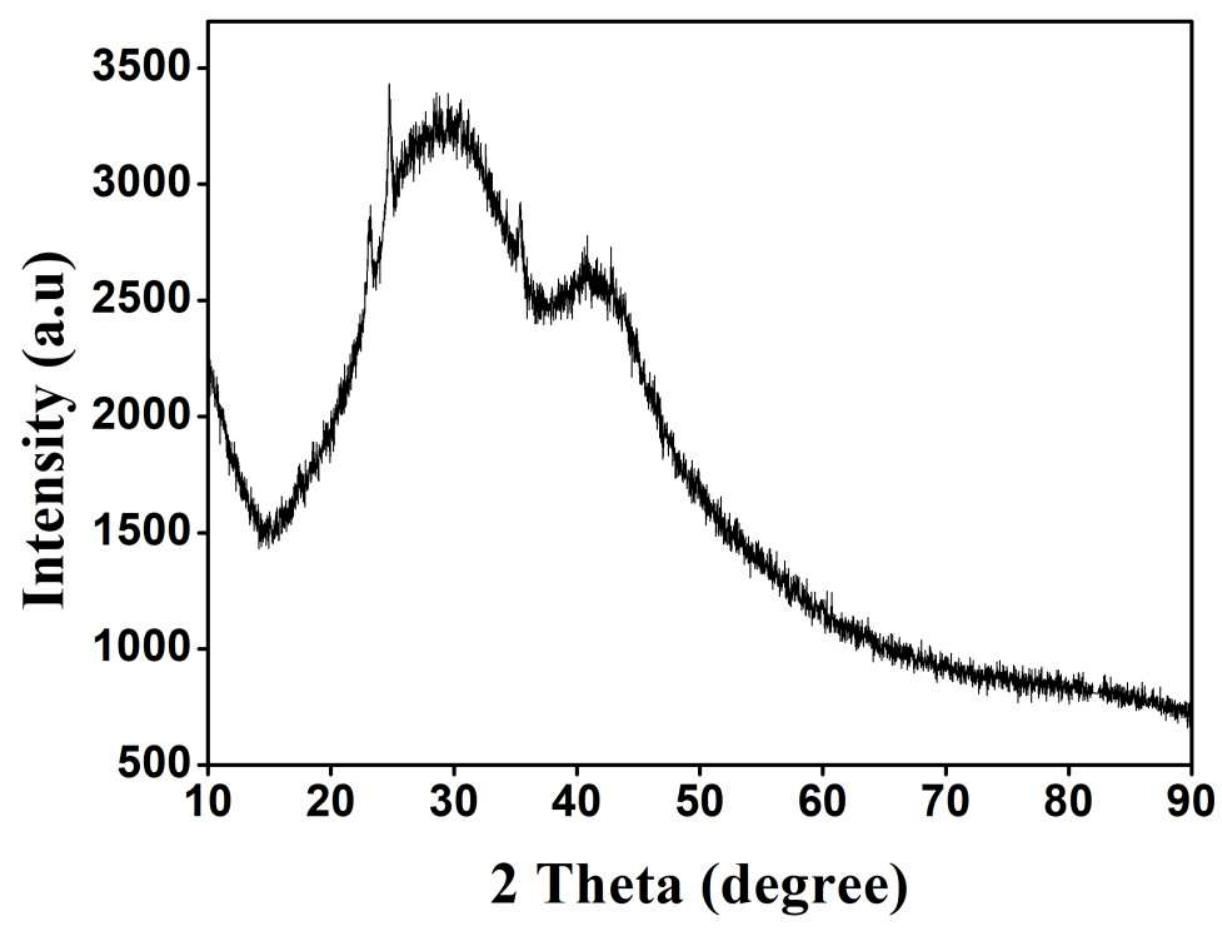

Fig.2. XRD pattern of 2.5 N PAB

196 efficiency among the selected biochars (Figure $3 \& 4$ ).
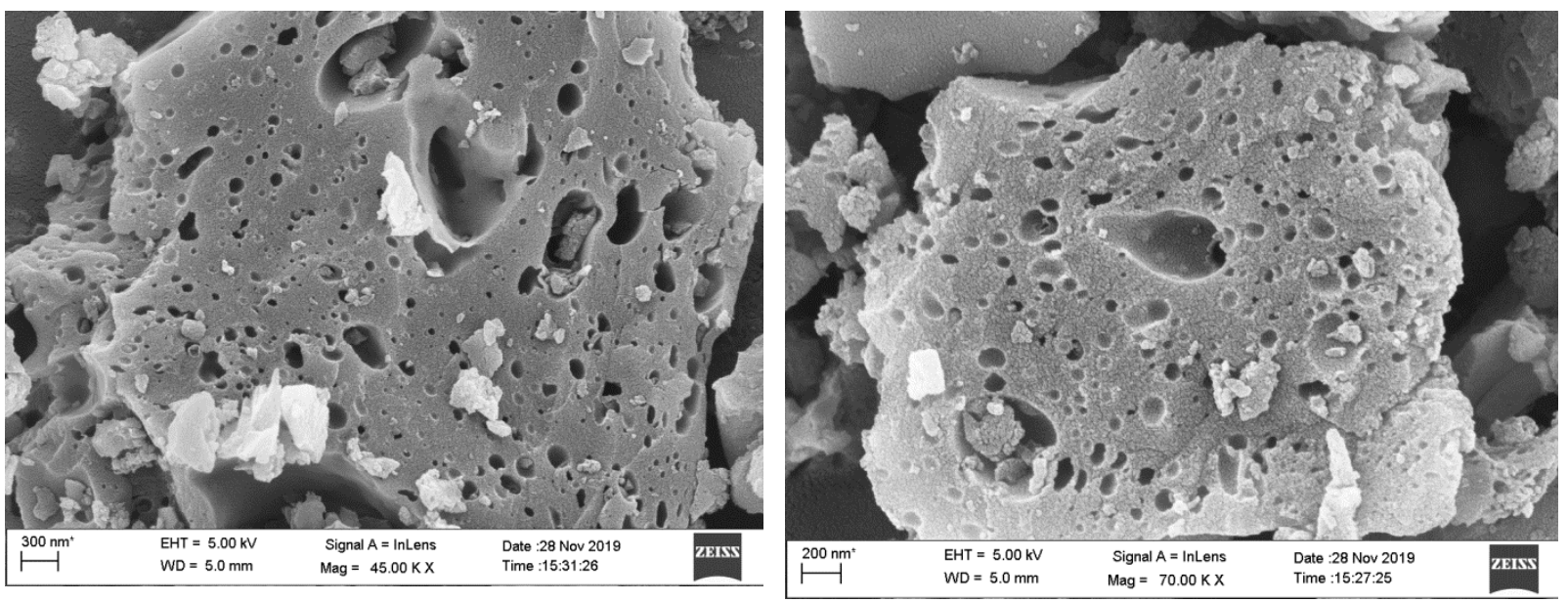

Fig. 3. Scanning electron micrograph images of $2.5 \mathrm{~N} \mathrm{PAB}$ at various magnifications 
The surface of the biochar with irregular shaped pores $(2-50 \mathrm{~nm})$ are visible in the SEM images. During the pyrolysis process, the acids react with oil cake and create pores due to the evaporation of volatile gases (Yue, 1995).

200 The number of pores per unit area produced by $\mathrm{H}_{3} \mathrm{PO}_{4}$ treated almond is high as confirmed by porosity studies. The 201 size and shape of the pores are found to be non-uniform. The highly porous structure of the biochar can account for the higher methylene blue value and color removal efficiencies. The EDX analysis depicted that the $2.5 \mathrm{~N}$ PAB is rich in carbon content (83.67). In addition to carbon and oxygen, a negligible quantity of $\mathrm{P}, \mathrm{Mg}, \mathrm{Ca}$, and $\mathrm{Si}$ were also detected.

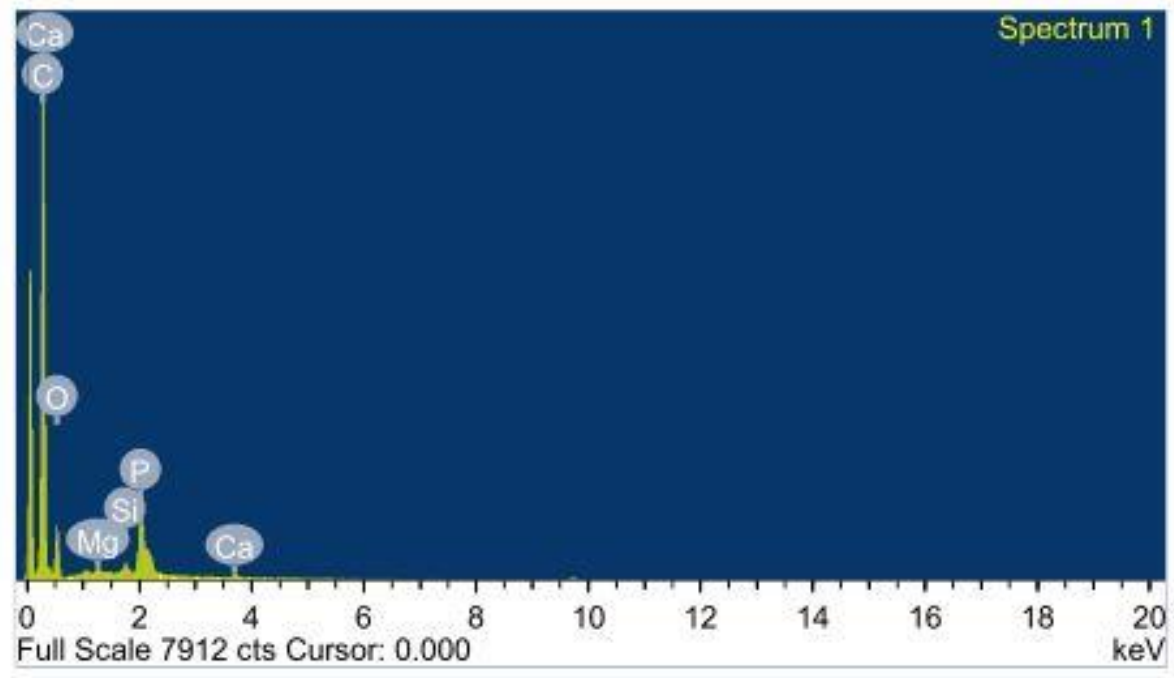

Fig. 4. EDX spectra of $2.5 \mathrm{~N} P A B$

\subsection{BET analysis}

One of the critical parameter of biochar is its BET surface area to characterize the adsorption phenomenon.

209 The BET analysis of 2.5 N PAB was performed as described earlier and the results are tabulated in Figure 5.There is 210 robust association exists between the carbon content of the biochar and BET surface area. Pyrolysis leads to the 211 degradation of organic material of oil cakes and improves the surface area of $85.78 \mathrm{~m}^{2} / \mathrm{g}$. There have also been 212 plausible studies of similar findings elsewhere (Thangalazhy-Gopakumar et al., 2015). The surface area of biochar 213 produced from biomass is less than that of activated carbon produced from the same sources due to low temperature

214 pyrolysis (Batista et al., 2018). The pore radius and pore volume $(0.70 \mathrm{~nm}$ and $0.056 \mathrm{cc} / \mathrm{g})$ indicate the presence of 215 herbaceous biochars. The specific surface area, pore volume and pore radius of biochar are highly depend on the raw 216 material, activating chemical and pyrolysis temperature due to the variation in the decomposition of organic matters 217 (Tomczyk et al., 2020). 


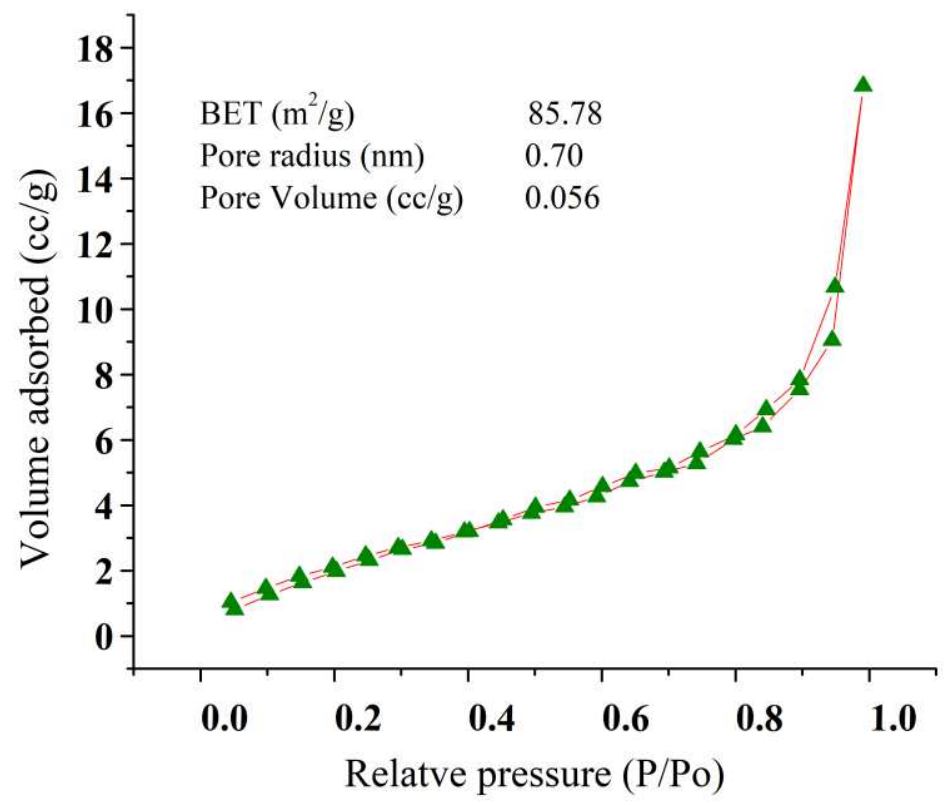

Fig. 5. BET analysis image of $2.5 \mathrm{~N} \mathrm{PAB}$

As mentioned earlier, the batch adsorption experiments were conducted with the acid dye effluent.

222 Immediately after dyeing, the absorbency of the acid dye effluent was found to be 1.27.

223 In all the selected biochars, there observed an increasing trend in the color removal with respect to time and

224 concentration of adsorbent. Poor color removal efficiencies were recorded with all biochars at low concentrations of 225 weight percentage of 0.5 and $1.0 \%$ and saturation of the adsorption exists and no further decolorization occur. 226 Increasing the weight percentage of adsorbent from 1.5 to $2.0 \%$ resulted in better color removal and attains 227 equilibrium near $90 \mathrm{~min}$. Whilst, among three biochars of $1.5 \%$ concentrations, the efficiency was found to be the 228 highest in the case of $2.5 \mathrm{~N}$ PAB than the other two biochars as demonstrated in Figure 6 (a). The adsorption studies on color removal from acid dye bath using various concentrations of $2.5 \mathrm{~N}$ PAB is shown in Figure 6 (b). 

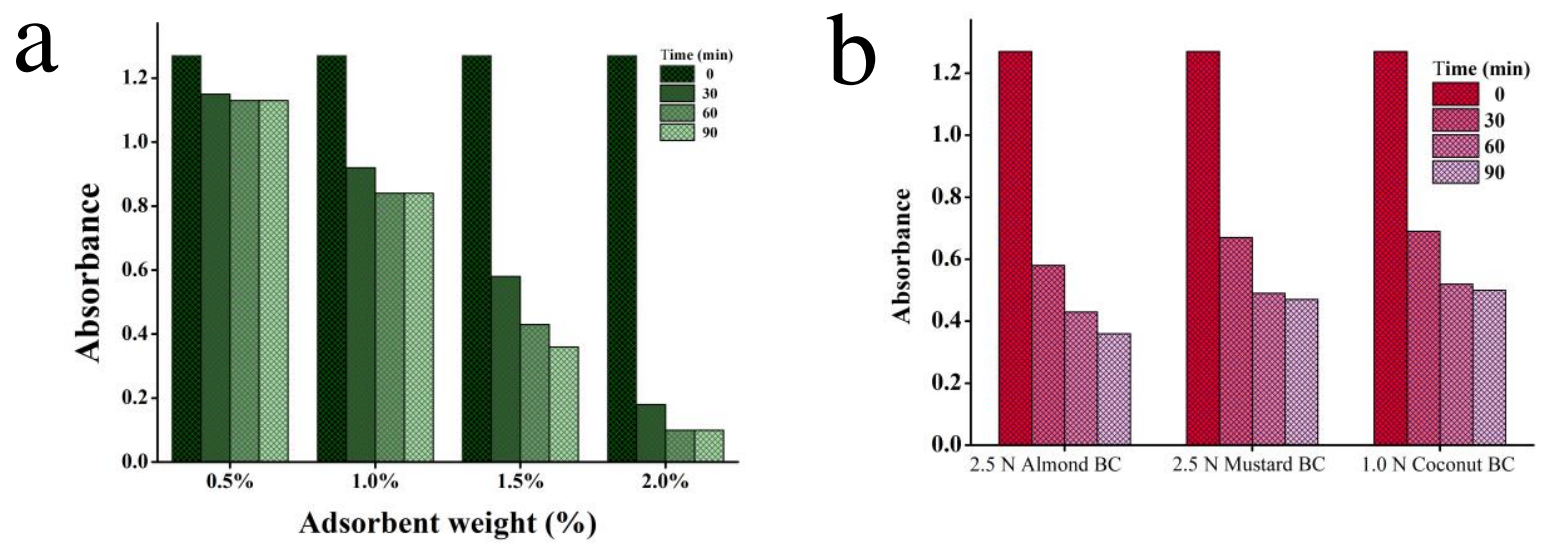

231 Fig.6. (a) Batch adsorption studies on acid dye removal using 1.5weight percentage of phosphoric acid treated 232 bichars and (b) batch adsorption studies on acid dye removal using 2.5 NPAB

Among the different weight percentages of biochars $(0.5,1.0,1.5$, and $2.0 \%)$ used for the adsorption studies, the $2.0 \%$ biochar found to be more effective in removing the color in all selected oil cakes. The $2.5 \mathrm{~N}$ PAB at the weight percentage of $2.0 \%$ resulted the highest color removal with an absorbency value of 0.1 .

\subsection{Kinetic studies}

The experimental and calculated values of $k_{1}, k_{2}, q_{e}$ and regression coefficient values $\left(\mathrm{R}^{2}\right)$ for acid dyes are given in table 3. Pseudo first order kinetic model fit linearly up to 30 to 40 minutes with regression values of 0.99 , showing that the attainment of saturation of active sites takes place depending upon amount of adsorbent. The pseudo second order kinetics fit well with rate expression with $\mathrm{R}^{2}$ values showing that the rate of adsorption equilibrium capacity increases with amount of adsorbent (Fig 7). The results revealed that the saturation of

242 adsorbent attained at a lower adsorbent percentage and the rate of adsorption augment with an increase in weight

243 percentage of adsorbent. The amount of acid dye adsorbed on 2.5 N PAB is found to be quite high may result from 244 high methylene blue value as in Table 2. 


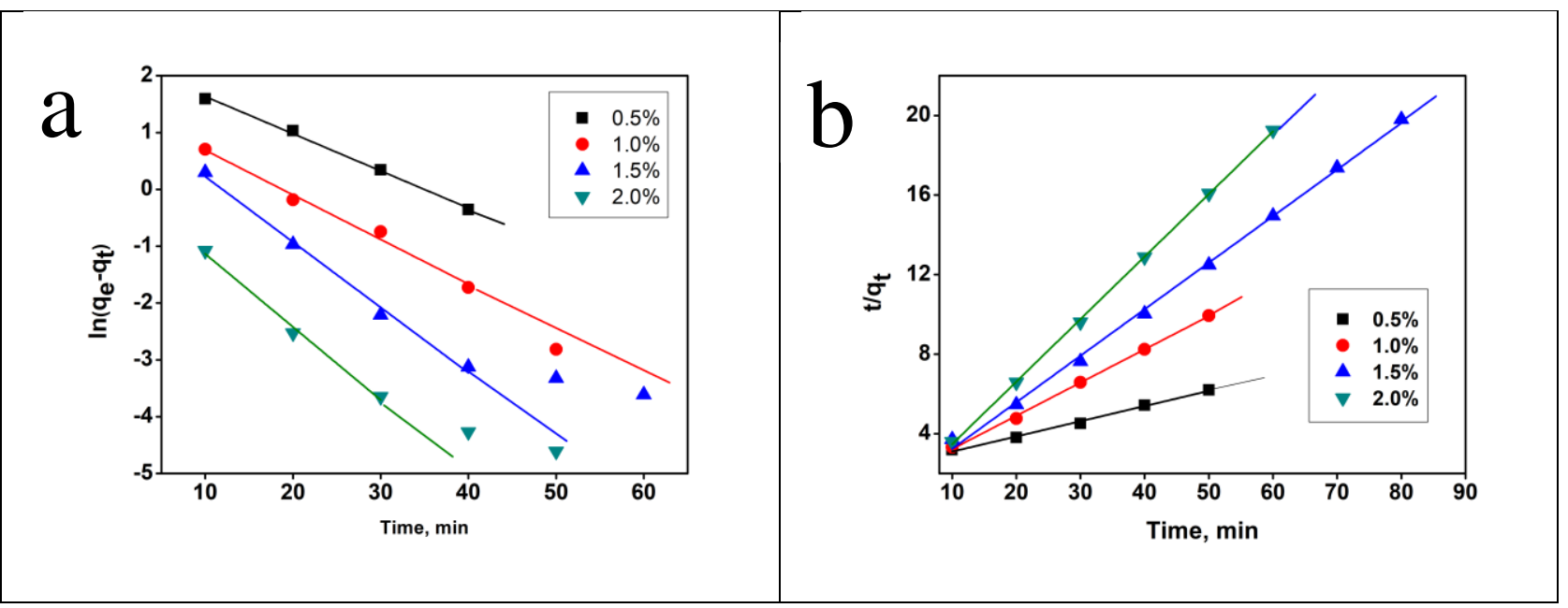

Fig.7. Kinetic plots of adsorption of acid dye on 2.5 N PAB (a) Pseudo first order (b) Pseudo-second order

Table 3. Pseudo-first order and pseudo-second order values for acid dye adsorption by $2.5 \mathrm{~N}$ PAB

\begin{tabular}{|c|c|c|c|c|c|c|c|}
\hline \multirow{2}{*}{$\begin{array}{l}\text { Adsorbent in } \\
\text { weight }(\%)\end{array}$} & \multirow{2}{*}{$\begin{array}{l}\text { Experimental } \\
q_{e}\left(\mathrm{mg} \cdot \mathrm{g}^{-1}\right)\end{array}$} & \multicolumn{3}{|c|}{ Pseudo first order } & \multicolumn{3}{|c|}{ Pseudo second order } \\
\hline & & $\begin{array}{c}q_{e} \\
\left(\mathrm{mg} \cdot \mathrm{g}^{-1}\right)\end{array}$ & $\begin{array}{c}k_{1} \\
\left(\mathrm{~min}^{-1}\right)\end{array}$ & $R^{2}$ & $\begin{array}{c}q_{e} \\
\left(\mathrm{mg} \cdot \mathrm{g}^{-1}\right)\end{array}$ & $\begin{array}{c}k_{2} \\
\left(\mathrm{~g} \cdot \mathrm{mg}^{-1} \mathrm{~min}^{-1}\right)\end{array}$ & $R^{2}$ \\
\hline 0.5 & 8.06 & 9.87 & 0.0654 & 0.99 & 13.11 & 0.0025 & 0.99 \\
\hline 1.0 & 5.03 & 4.37 & 0.0700 & 0.99 & 05.99 & 0.0179 & 0.99 \\
\hline 1.5 & 4.04 & 3.96 & 0.1151 & 0.99 & 04.28 & 0.0607 & 0.99 \\
\hline 2.0 & 3.12 & 1.16 & 0.1285 & 0.99 & 03.18 & 0.2999 & 0.99 \\
\hline
\end{tabular}

\section{Conclusion}

Currently, petroleum-based activated carbon is successfully employed to remove the residual color from the textile effluent. Textile industries are always searching for efficient replacement of existing high-cost materials for effluent treatment. In this context, an attempt was made to prepare biochars from low-cost oil cakes and used it for the removal of color from the acid dye from wool dye effluent collected from the pilot plant. Phosphoric acid treatment followed by a low temperature pyrolysis converted the oil cakes into biochars. The micro and nano-sized pores produced inside the biochar was found to be effective for the dye adsorption. Whilst the same protocol was employed for the preparation of biochars from all oil cakes, the biochar developed from almond was found to have 
better efficiency than others with $92 \%$ color removal efficiency. Due to the low temperature pyrolysis, though the performance of the synthesized biochars is expected to be slightly lesser than the commercial activated carbon produced from petroleum products, the cost may be justified with low cost precursor. Acid dyes are commonly employed for the dyeing of wool fabric. In comparison with reactive dyeing of cotton, due to the high affinity of acid dyes on wool, they produce very few remnant dyes in the dye bath. Here, the high-cost activated carbon may be partially or fully replaced with low-cost biochars produced from agro residues. The study concluded that the biochars produced from low cost agro processing residue - oil cakes can effectively transform into high-value biochars and the said biochars can be used for the removal of color from acid dye effluent from wool dye house.

\section{References}

Adel AM, Abd El-Wahab ZH, Ibrahim AA, Al-Shemy MT (2011) Characterization of microcrystalline cellulose prepared from lignocellulosic materials. Part II: Physicochemical properties. Carbohydr. Polym 83(2):676-687

Basu G, Mishra L, Jose S, Samanta AK (2015) Accelerated retting cum softening of coconut fibre. Ind Crop Pro 77:66-73

Batista EM, Shultz J, Matos TT, Fornari MR, Ferreira TM, Szpoganicz B, de Freitas RA, Mangrich AS (2018) Effect of surface and porosity of biochar on water holding capacity aiming indirectly at preservation of the Amazon biome. Sci. Rep 8(1):1-9

Crini G (2006) Non-conventional low-cost adsorbents for dye removal: a review. Bioresour. Technol 97(9):10611085

277 Copaciu F, Opriş O, Niinemets Ü, Copolovici L (2016) Toxic influence of key organic soil pollutants on the total 278 flavonoid content in wheat leaves. Water Air Soil Pollut 227(6):1-10

279 Dawood S, Sen TK, Phan C (2017) Synthesis and characterization of slow pyrolysis pine cone bio-char in the removal of organic and inorganic pollutants from aqueous solution by adsorption: kinetic, equilibrium,

282 Ding W, Dong X, Ime IM, Gao B, Ma LQ (2014) Pyrolytic temperatures impact lead sorption mechanisms by 283 bagasse biochars. Chemosphere 105:68-74

284 Downie A, Crosky A, Munroe P (2012) Physical properties of biochar. In Biochar for environmental management, Routledge pp 45-64 
Girgis BS, Temerk YM, Gadelrab MM, Abdullah ID (2007) X-ray diffraction patterns of activated carbons prepared under various conditions. Carbon lett 8(2):95-100

Jose S, Mishra L, Basu G, Kumar Samanta A (2017) Study on Reuse of Coconut Fiber Chemical Retting Bath. Part II---Recovery and Characterization of Lignin. J. Nat. Fibers 14(4):510-518

Jose S, Samant L, Bahuguna A, Pandit P (2020) Opportunities of Agro and Biowaste in the Fashion Industry. Recycling from Waste in Fashion and Textiles: A Sustainable and Circular Economic Approach pp73-100

Jose S, Shanmugam N, Kumar A, Das S (2020) Removal of Basic Violet from Wool Dyeing Effluent Using Nanoparticles. J. Nat. Fibers 19:1-11

Mohan SV, Karthikeyan J (2004) Adsorptive removal of reactive azo dye from an aqueous phase onto charfines and activated carbon. Clean Technol Environ Policy 6(3):196-200

Norouzi S, Heidari M, Alipour V, Rahmanian O, Fazlzadeh M, Mohammadi-Moghadam F, Nourmoradi H, Goudarzi B, Dindarloo K (2018) Preparation, characterization and Cr (VI) adsorption evaluation of NaOHblue and iodine numbers. Quim. Nova 34:472-476 activated carbon produced from Date Press Cake; an agro-industrial waste. Bioresour. Technol 258:48-56

Nunes CA, Guerreiro MC (2011) Estimation of surface area and pore volume of activated carbons by methylene

Panahi HK, Dehhaghi M, Ok YS, Nizami AS, Khoshnevisan B, Mussatto SI, Aghbashlo M, Tabatabaei M, Lam SS (2020) A comprehensive review of engineered biochar: production, characteristics, and environmental applications. J. Clean. Prod. 270:122462

Pandey R, Patel S, Pandit P, Nachimuthu S, Jose S (2018) Colouration of textiles using roasted peanut skin-an agro processing residue. J. Clean. Prod. 172:1319-1326

Partlan E, Davis K, Ren Y, Apul OG, Mefford OT, Karanfil T, Ladner DA (2016) Effect of bead milling on chemical and physical characteristics of activated carbons pulverized to superfine sizes. Water res 89:161-170

Pongener CH, Kibami DA, Rao KS, Goswamee RL, Sinha D (2015) Synthesis and Characterization of Activated Carbon from the Biowaste of the Plant Manihot esculenta. Chem. Sci. Trans 4(1):59-68

310 Ramachandran S, Singh SK, Larroche C, Soccol CR, Pandey A (2007) Oil cakes and their biotechnological applications-A review. Bioresour. Technol 98(10):2000-2009

312 Samant L, Jose S, Rose NM, Shakyawar DB (2020) Antimicrobial and UV protection properties of cotton fabric using enzymatic pretreatment and dyeing with Acacia catechu. J. Nat. Fibers 26:1-11 
314 Shi J, Li J (2012) Metabolites and chemical group changes in the wood-forming tissue of Pinus koraiensis under 315 inclined conditions. Bio Resources 7(3):3463-3475

316 Liu C, Shi W, Li H, Lei Z, He L, Zhang Z (2014) Improvement of methane production from waste activated sludge 317 by on-site photocatalytic pretreatment in a photocatalytic anaerobic fermenter. Bioresour. Technol 155:198-203

318 Tomczyk A, Sokołowska Z, Boguta P (2020) Biochar physicochemical properties: pyrolysis temperature and 319 feedstock kind effects. Rev. Env. Sci. Biotechnol 19(1):191-215

320 Vaughn SF, Dinelli FD, Jackson MA, Vaughan MM, Peterson SC (2018) Biochar-organic amendment mixtures 321 added to simulated golf greens under reduced chemical fertilization increase creeping bentgrass growth. Ind 322 Crop Pro 111:667-672

323 Wang J, Wang S (2019) Preparation, modification and environmental application of biochar: a review. J. Clean. 324 Prod. 227:1002-1022

325 Yuan T, He W, Yin G, Xu S (2020) Comparison of bio-chars formation derived from fast and slow pyrolysis of 326 walnut shell. Fuel 261:116450

327 Yakout SM, El-Deen GS (2016) Characterization of activated carbon prepared by phosphoric acid activation of 328 olive stones. Arab.J.Chem. 9:S1155-S1162

329 Yue, Z.R (1995) Preparation of activated carbon fibers and adsorption mechanism of Ag+ .Ph.D. dissertation. 330 Zhongshan University, Guangzhou. 


\section{Supplementary Files}

This is a list of supplementary files associated with this preprint. Click to download.

- Graphicalabstract.jpg 